\begin{tabular}{|c|c|}
\hline \multirow{3}{*}{ 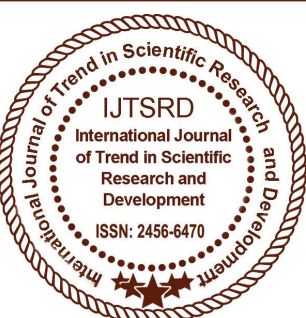 } & $\begin{array}{l}\text { International Journal of Trend in Scientific } \\
\text { Research and Development (IJTSRD) }\end{array}$ \\
\hline & International Open Access Journal \\
\hline & ISSN No: 2456 - 6470 | www.ijtsrd.com | Volume - 2 | Issue - 5 \\
\hline
\end{tabular}

\title{
Two Dimensional Filter Design Using Evolutionary Optimization
}

\author{
Kumari Divya $^{1}$, Mrs. Kiran Dewangan ${ }^{2}$ \\ ${ }^{1}$ M.Tech Scholar, ${ }^{2}$ Assistant Professor \\ Deptpartment of Electronics Engineering, Bhilai Institute of Technology, \\ Durg, Chhattisgarh, India
}

\begin{abstract}
In the last few years design of two dimensional has grown sufficient zest among researchers. The design of two dimensional finite impulse response (FIR) filters can be expound as a non-linear optimization problem. The constraints are high and estimation of large number of parameters is needed, especially in case of two dimensional finite impulse response filters. In order to improve performance we have used Binary Cat Swarm Optimization (BCSO) in which some concepts are introduced to bring down ripples.
\end{abstract}

Keywords: Finite impulse response, optimization, $B C S O$

\section{INTRODUCTION}

Two dimensional(2D) digital filter have found wide applications in different areas like image processing [1], seismic signal processing, nuclear test detection, sonar, radar and radio astrology [2]. In the area of image processing, 2D FIR filters are preferred because of their inherently stable nature, no phase distortion and easy realization using fast Fourier Transform. They are used for image contrast enhancement, denoising [3], [4], image deblurring and image restoration [5]. The classical techniques for designing 2D filters are extension of $1 \mathrm{D}$ techniques, these include windowing [6], frequency sampling[7], chebysev approximation [8], McClellan transformation [2] and least squares. Windowing is the simplest technique for magnitude response but it fails in linear phase of 2D filters [6]. In addition to the classical techniques some optimization based approaches has been successfully applied for 2D FIR filter design.
Optimization based filter design techniques aims at meeting the desired specifications by minimizing a predefined objective function. The techniques reported in this regards can be broadly classified into two groups, i.e., classical gradient and heuristic evolutionary techniques. Gradient based techniques; inspite of having faster convergence, quite often gets trapped into local minima. Also the final solution to these techniques is very sensitive to the initial parameterization. Evolutionary optimization (EA) because of their ability to mimic the intelligence of natural selection and adoption process found in biological species, have been successfully applied for the solution of complex nonlinear optimization problem in different engineering fields including FIR filter design. In this regard, the optimization techniques adopted for 2D FIR filter includes simulated annealing[9], clonal section algorithm[10], genetic algorithm(GA)[11], cat swarm optimization[12].Most of the above reported techniques suffer from the limitations of tuning, selection of large number of control parameters and large execution time. In this context, a recently developed evolutionary technique i.e., modified binary cat swarm optimization has been applied in the present work for the design of FIR filters.

\section{METHODOLOGY}

The Binary cat swarm optimization is an optimization algorithm that imitates the natural behavior of cats. Cats have curiosity about objects in motion and have a great hunting ability. It might be thought that cats spend most of the time resting, but in fact they are constantly alert and moving slowly. This behavior corresponds to the seeking mode. Furthermore, when cats detect a prey, they spend lots of energy because 
of their fast movements. This behavior corresponds to the tracking mode. In $\mathrm{BCSO}$, these two behaviors are modeled mathematically to solve complex optimization problems. In BCSO, the first decision is the number of cats needed for each iteration. Each cat represented by catk, where, $\mathrm{k}$ belongs to $(1, \mathrm{C})$, has its own position consisting of $\mathrm{M}$ dimensions, which are composed by ones and zeros. Besides, they have speed for each dimension $\mathrm{d}$, a flag for indicating if the cat is on seeking mode or tracking mode, and finally a

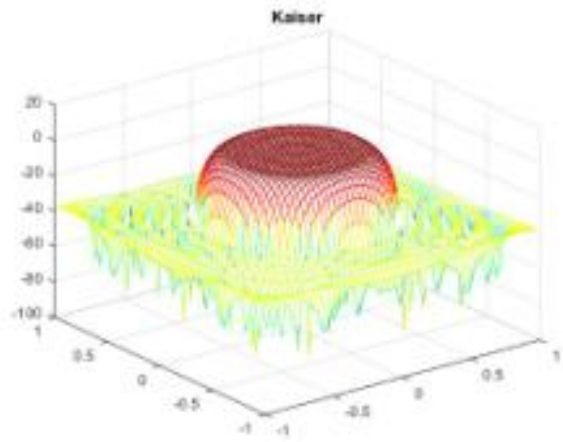
fitness value that is calculated based on the SCP. The BCSO keeps searching for the best solution until the end of iterations.

Tables

\begin{tabular}{|l|l|l|l|l|}
\hline $\begin{array}{c}\text { S. } \\
\text { No }\end{array}$ & Algorithm & PBR & SBR & SBA \\
\hline 1 & $\begin{array}{l}\text { Kaiser } \\
\text { Window }\end{array}$ & 0.090876 & 0.090876 & -20.831022 \\
\hline 2 & PM & 0.162730 & 0.162382 & -15.789259 \\
\hline 3 & GA & 0.77008 & 0.45669 & -26.807494 \\
\hline 4 & CSO & 0.095017 & 0.023003 & -32.76446 \\
\hline 5 & BSCO & 0.174372 & 0.017882 & -34.951812 \\
\hline
\end{tabular}

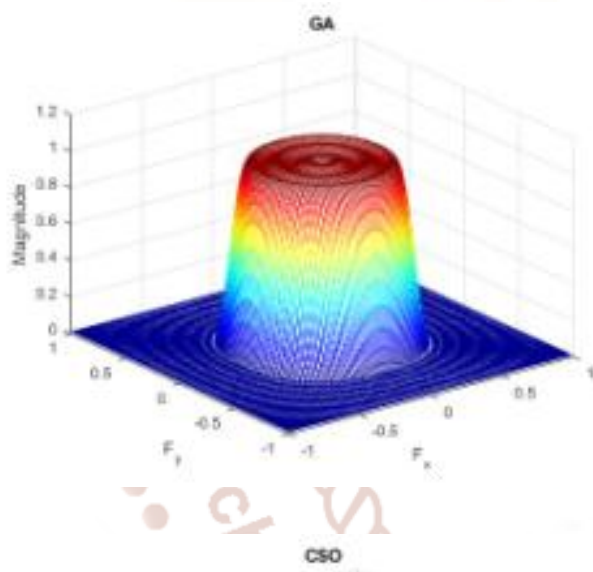

\section{RESULT AND DISCUSSION}

We have designed FIR filter which has some of its specifications such as pass band, stop band ripples which are needed to be minimized. For minimizing this we have designed filter and compared it with different types of algorithm to monitor ripples. Following are results of comparison
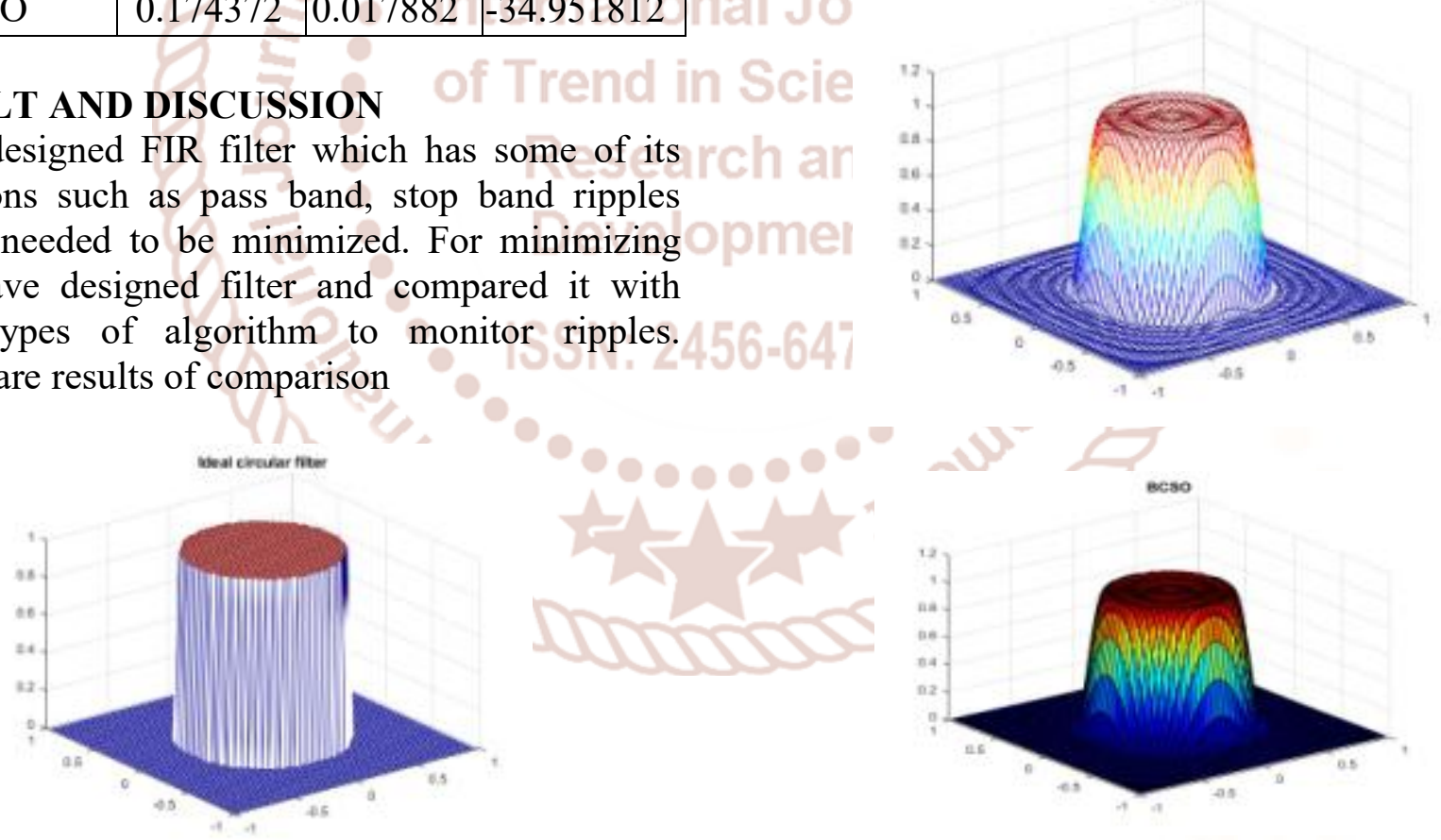

Comparison graph between $\mathrm{CSO}$ and $\mathrm{BCSO}$ 
International Journal of Trend in Scientific Research and Development (IJTSRD) ISSN: 2456-6470

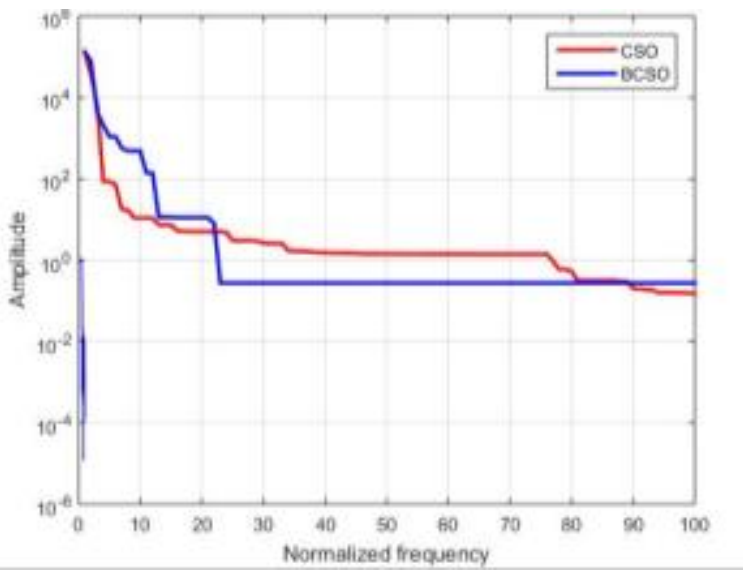

\section{CONCLUSION AND FUTURE SCOPE}

In this paper, the two dimensional FIR filter task has been framed as an optimization problem with objectives of minimizing PBR, SBR and SBA. Here we have designed filter using binary cat swarm optimization after that we have compared it with parameters such as pass band ripples, stop band ripples of different types of algorithm that is cat swarm optimization, Kaiser window, Genetic algorithm, Parks-McClellan, Binary cat swarm optimization. After all this comparison we have concluded that we are getting minimum ripples with binary cat swarm optimization. For any particular application we can specially design this so that we can modify it as per our requirements. Using some recent technique we can design according to that recent technique Low power processor can be designed. Multi objective filters can be designed Can be applied to filters such as seismic, vibrational. This two dimensional filter can be designed to multidimensional that is three dimensional, four dimensional and so on as per requirement.

\section{REFERENCES}

1. S. Kockanat and N. Karaboga, "The design approaches of two-dimensional digital filters based on metaheuristic optimization algorithms: a review of the literature," Artif. Intell. Rev., vol. 44, no. 2, pp. 265-287, Aug. 2015.

2. R. Mersereau, W. Mecklenbrauker, and T. Quatieri, "McClellan transformations for twodimensional digital filtering-Part I: Design," IEEE Trans. Circuits Syst., vol. 23, no. 7, pp. 405-414, Jul. 1976.

3. S. Kockanat, N. Karaboga, and T. Koza, "Image denoising with 2-D FIR filter by using artificial bee colony algorithm," in 2012 International Symposium on Innovations in Intelligent Systems and Applications, 2012, pp. 1-4.

4. A. Chandra and S. Chattopadhyay, "A new strategy of image denoising using multiplier-less FIR filter designed with the aid of differential evolution algorithm," Multimed. Tools Appl., vol. 75, no. 2, pp. 1079-1098, 2014.

5. I. Ahmad, P. Mondal, and R. Kanhirodan, "A New FIR Filter for Image Restoration," in 2006 1ST IEEE Conference on Industrial Electronics and Applications, 2006, pp. 1-6.

6. T. Huang, "Two-dimensional windows," IEEE Trans. Audio Electroacoust., vol. 20, no. 1, pp. 88-89, Mar. 1972.

7. J. Hu and L. Rabiner, "Design techniques for twodimensional digital filters," IEEE Trans. Audio Electroacoust., vol. 20, no. 4, pp. 249-257, Oct. 1972.

8. Y. Kamp and J. Thiran, "Chebyshev approximation for two-dimensional nonrecursive digital filters," IEEE Trans. Circuits Syst., vol. 22, no. 3, pp. 208-218, Mar. 1975.

9. J. Radecki, J. Konrad, and E. Dubois, "Design of multidimensional finite-wordlength FIR and IIR filters by simulated annealing," IEEE Trans. Circuits Syst. II Analog Digit. Signal Process., vol. 13, no. 6, pp. 424-431, Jun. 2005.

10. T. J. J. Su, C. H. H. Kuo, W. P. P. Tsai, and C. C. C. Hou, "A hybrid of clonal Selection Algorithm and Frequency Sampling Method for designing a 2-D FIR filter," Proc. - 4th IEEE Int. Symp. Electron. Des. Test Appl. DELTA 2008, pp. 274278, Jan. 2008.

11. S.-T. Tzeng, "Design of 2-D FIR digital filters with specified magnitude and group delay responses by GA approach," Signal Processing, vol. 87, no. 9, pp. 2036-2044, Sep. 2007.

12. M. Bahrami, O. Bozorg-haddad, and X. Chu, "Cat Swarm Optimization ( CSO ) Algorithm," pp. 919, 2018. 